\title{
EDITORIAL
}

\section{On the continued growth of the ERJ}

\author{
U. Costabel
}

The European Respiratory Journal (ERJ) is still a young journal, serving as a worldwide scientific platform for all aspects of respiratory medicine and research. It is the official journal of the European Respiratory Society (ERS) which is even younger than the Journal. The growth both of the Journal and the Society, has been tremendous during their short life. The ERJ was born in 1988 when the European Journal of Respiratory Diseases (EJRD) owned by Munksgaard was merged with the Bulletin Européan Physiopathologie Respiratoire owned by the European Society for Clinical Respiratory Physicians (SEPCR). There is no doubt that the ERJ was an attractive dowry in the marriage between SEPCR and SEP $[1,2]$.

The growth of the journal can be seen at several measurable levels. Firstly, the number of submitted and published manuscripts. In 1994, the Journal received 829 manuscripts. This was 131 papers or about $20 \%$ more than in 1993, and almost twice as many as back in 1990 . So far this year (15 December 1995) 987 papers have already been received. The acceptance rate has been around $40 \%$ over the years. In 1988, 10 issues and about 1,000 pages were published; there was a stepwise increase to 12 issues and 2,314 pages in 1994. Despite the increase in workload for all those involved in the running of the journal, the handling times for the papers remained satisfactory. Since 1992, the mean verdict time, that is the time from the received date to the first decision made by the associate editor on revision or rejection, has been 61 days. The production time (from acceptance to publication date) was only 4 months in 1993 and 1994, and could be reduced to 3.5 months in 1995 . The total handling time for the published manuscripts (from received to publication date) was 10 months in 1994.

The second level of growth has been the scientific quality of the published papers. In this regard, the increased number of papers handled by the journal has not been compromised by a loss of quality. The measurable index for the scientific standard, the impact factor continues to grow. The score was 1.12 in 1990, 1.27 in 1991, 1.5 in 1992, 2.0 in 1993 and 2.11 in 1994.

The third level of growth has been the size of the Editorial Board. The number of associate editors had to be enlarged from 21 in 1988 to 40 in 1995. Each associate editor handles on average 20 manuscripts per year, some of them up to 35 , depending on the topics which they take care of. Surgical and epidemiological papers are still fewer in number than those from other fields. Since the last update on Editorial matters in 1993 [3], the following members have left the Board: S. Anderson,
P.J. Barnes, J. Boe, R. Dahl, W. De Backer, M. Decramer, F. Kauffman, T. Lee, R. Loddenkemper, H. Lode, K. Moghissi, P. Paoletti, E. Puchelle, R. Rodrigeuz-Roisin, C. Roussos and D. Stanescu. We very much thank them for their work. Peter Sterk will continue as Assistant Chief Editor in the final editing of accepted manuscripts and in the general scientific management and will now be joined by Robert Naeije. Leo Fabbri will remain the Chief Editor of the European Respiratory Review for one more year.

Several growth factors in concert have driven this successful development of the ERJ. Firstly, the authors who submit their best work. Secondly, the readers who recognize the ERJ as a major journal in their field and eagerly read and cite it. Thirdly, the associate editors and the troupe of numerous anonymous reviewers, who help to remain selective and to keep the scientific excellence of the published work. Fourthly, the Journal production in Sheffield, with Peter Howard as Managing Editor, Celia Emery as Technical Editor and Wendy Thompson as the Production Manager, who over the years have effectively improved the layout, the linguistic correctness, the optical appearance of the figures and the overall printing quality.

The Journal is now facing a period of transition, since several important "growth factors" have left or now leave prominent positions. I will mention them briefly.

Erik Berglund was the "Senior" of the past Chief Editors. I learned from him the meticulous screening of papers during the final editing procedure for inconsistencies between questions and answers, between data presented in the abstract and in the main text, and for the misuse of statistics. In this regard, his "favourite" was and is the revealing of inappropriate drawing of regression lines, a misdeed which is still frequent today. Erik has a fine and sensitive eye for such flaws overlooked by reviewers and associate editors. When I started as new associate editor in 1990 and had finished the handling of the first paper to be accepted, I proudly sent it to Erik for final decision. The pride was gone after receiving a copy of Erik's letter to the authors requiring further changes including the redrawing of regression lines.

Jean-Claude Yernault was the first Chief Editor to leave the ERJ after 2 yrs but only to continue to serve with his editorial capacities for the ERS, first as Editor of the European Respiratory Review, next as Editor of the European Respiratory Topic, and finally when creating, together with Leo Fabbri, the new educational book series called the European Respiratory Monograph. No one 
knows which publication project Jean-Claude will bear next in his mind.

Paul Vermeire is to be admired for his ability to communicate with unhappy authors, who complain about unfair rejection of what they think is important work. Some authors have been lucky and have had the chance to resubmit a completely revised and newly written paper, when Paul felt that the authors' critique on the reviewers' comments was somewhat justified. Paul and his secretary, Greta Van de Vyver, organized the Antwerp office in a very efficient way. The main editorial office was smoothly transferred from Antwerp to Essen in 1995. I am very glad that Paul, following his decision to resign as Chief Editor, has agreed to remain on the board with his great editorial expertise, as Erik Berglund has done.

Peter Howard has been a unique and somewhat baroque manager, combining excellence in pulmonary medicine, publishing and business. It might prove difficult to find another person with this unusual combination of various skills.
Philip Quanjer engineered the merging of the EJRD and the Bulletin, and represented the ERS on the management board for many years. With his in-depth knowledge of the complicated structure of the contract between Munksgaard and the ERS, he was a strong and diplomatic partner in the new agreement with Munksgaard.

The ERJ and the ERS owe much gratitude to these personalities. For the future, I hope that the Journal will continue to meet the changing demands of scientific publishing, with the support from authors, readers, and the members of the ERS.

\section{References}

1. Junod AF, Clarke SW. The birth of the European Respiratory Society. Eur Respir J 1991; 4: 3.

2. Vermeire P, Berglund E. The ERJ as official journal of the ERS. Eur Respir J 1991; 4: 3-4.

3. Vermeire P. The ERJ two years later. Eur Respir $J$ 1993; 6: 11-12. 